\title{
MELANISM IN THE MOTH GONODONTIS BIDENTATA: A CLINE WITHIN THE MERSEYSIDE CONURBATION
}

\author{
J. A. BISHOP and P. S. HARPER \\ Deportment of Zoology and Department of Medicine, The University of Liverpool
}

Received 28.viii.69

\section{INTRODUCTION}

Kettlewell $(1958,1961)$ discussed the spread of melanic forms through populations of the moth Biston betularia. The main factor responsible was increased protection from predation by birds of melanic moths camouflaged against the darkened background of smoke-polluted tree trunks.

The melanics of a number of species of moth, however, are absent in some industrial and urban areas though they are known to be common in others. The melanic of Gonodontis bidentata appears to be absent from central Birmingham yet it forms 50 per cent. or more of the population at Cannock Chase $30 \mathrm{~km}$. away (Kettlewell, 1961). A similar situation seems to occur in some parts of London while in central Manchester melanics constitute up to 80 per cent. or more of the population (Askew, Bishop and Cook, 1971). In Birmingham the species supposedly " has had to resort to polygenic darkening " (Ford, 1964; Kettlewell, 1961) because of the failure of the mutation to the melanic form to occur and because it has not dispersed in from outside. Unlike male $B$. betularia which may fly several kilometres in a night (Kettlewell, 1958; Bishop, in preparation) male $G$. bidentata rarely fly more than $100 \mathrm{~m}$. a night (Bishop and Harper, in preparation).

The melanic of $G$. bidentata is controlled by an autosomal dominant gene as is the case in most species that show industrial melanism including $B$. betularia (Bowater, 1914; Sheppard, 1961). There is evidence that larvae with the gene may be hardier than those without it: Bowater (unpublished data quoted by Sheppard, 1961) obtained a non-significant excess of melanics in back-cross broods. The frequency of the melanic in a sample of $G$. bidentata taken from Broadgreen Hospital, Liverpool, in 1963 was about 45 per cent. yet the form was known to be rare in the Wirral Peninsula west of the River Mersey (C. A. Clarke, personal communication). This seemed to resemble the situation near Birmingham so the Merseyside populations were examined in order to distinguish between the following alternatives:

1. The melanic is spreading through a population from which it was previously absent.

2. A stable cline exists. If so there is a marked difference from $B$. betularia where the melanic, carbonaria forms more than 90 per cent. of most of the Liverpool and Wirral population (Clarke and Sheppard, 1966).

It was essential to conduct a survey of the Merseyside populations of $G$. bidentata to investigate these possibilities. The survey was greatly facilitated when Mr Tony Leibert discovered that larvae could easily be collected in the field. 


\section{THE SPECIES}

G. bidentata is common throughout Merseyside. Its larvae feed on a wide variety of food plants (South, 1948) but in built-up areas of Liverpool are usually found on privet. They occasionally are so abundant that they almost defoliate hedges in which they occur. Caterpillars are dark-grey in colour and show a striking resemblance to the blackened twigs of these hedges. During late October they pupate in silk cocoons on or just below the surface of the soil.

\section{TABLE 1}

Melanic and non-melanic Gonodontis bidentata caught in assembling traps at Broadgreen Hospital, Liverpool

$\begin{array}{cccc} & \text { Melanic } & \text { Non-melanic } & \text { Total } \\ 25 / 5 / 69-1 / 6 / 69 & 5 & 6 & 11 \\ 2 / 6 / 69-8 / 6 / 69 & 8 & 6 & 14 \\ 9 / 6 / 69 & 13 & 12 & 25 \\ 10 / 6 / 69 & 18 & 22 & 40 \\ 11 / 6 / 69 & 14 & 23 & 37 \\ 12 / 6 / 69 & 24 & 27 & 51 \\ 13 / 6 / 69 & 14 & 25 & 39 \\ 14 / 6 / 69 & 35 & 47 & 82 \\ 15 / 6 / 69 & 5 & 9 & 14 \\ 16 / 6 / 69 & 23 & 27 & 50 \\ 17 / 6 / 69 & 33 & 31 & 64 \\ 18 / 6 / 69 & 19 & 29 & 48 \\ 19 / 6 / 69 & 26 & 27 & 53 \\ 20 / 6 / 69 & 14 & 15 & 29 \\ 21 / 6 / 69 & 10 & 18 & 28 \\ 22 / 6 / 69 & 11 & 11 & 22 \\ 23 / 6 / 69 & 2 & 3 & 5 \\ 24 / 6 / 69 & 11 & 18 & 29 \\ 25 / 6 / 69 & 9 & 11 & 20 \\ 26 / 6 / 69-29 / 6 / 69 & 7 & 7 & 14 \\ \text { Total } & 301 & 374 & 675 \\ \% & 44 \cdot 6 & 55 \cdot 4 & \\ \text { Homogeneity } & \chi_{19}^{2}=8 \cdot 74 \text { (non-significant). }\end{array}$

Data consistent with hypothesis that there is no differential emergence of melanic and non-melanic moths and that the two forms fly in the same relative proportions throughout the season.

Adult G. bidentata fly from late May to late June in the North of England. The moth is nocturnal; it does not fly by day but we have not observed where it rests. Newly released individuals settle under ledges or fly to the centre of hedges and bushes. They may hold their wings in the horizontal plane but also show the habit, shared by related species, of holding them upright in a manner that resembles the resting attitude of a butterfly. The outer margins of the wings are scalloped which suggests that the moth is a leaf mimic.

There is no obvious difference in the time of emergence of the melanic and non-melanic moths. Table 1 records details of a large sample collected throughout the flying season of 1969 at Broadgreen Hospital, Liverpool. These data were subjected to a heterogeneity test which showed no evidence 
for differential emergence. This conclusion was supported by the pattern of emergence of moths from pupae kept in the laboratory (table 2).

TABLE 2

Emergence from pupal cases of a sample of moths. (Collected Site 10, Newsham, Liverpool)

$\begin{array}{cccc}\begin{array}{c}\text { Dates of } \\ \text { emergence } \\ (1969)\end{array} & \text { Melanics } & \text { Non-melanics } & \text { Total } \\ 13 / 5-30 / 5 & 7 & 11 & 18 \\ 31 / 5-10 / 6 & 12 & 7 & 19 \\ 11 / 6-20 / 6 & 16 & 31 & 47 \\ 21 / 6-28 / 6 & 6 & 12 & 18 \\ \text { Total } & 41 & 61 & 102 \\ \% & 40 \cdot 2 & 59 \cdot 8 & \end{array}$

Homogeneity $\chi_{3}^{2}=5 \cdot 332$ (non-significant).

Data consistent with hypothesis that there is no differential emergence of melanic and non-melanic moths from pupal cases.

\section{Methods}

Populations of larvae and adult males were sampled. Larvae were collected during October 1968 and fed on privet until they pupated. The moths were scored and sexed as they emerged in May and June 1969. Samples of larvae were taken by diligently searching a number of hedges at one site; bias would be inevitable if there were major differences in the behaviour of the two forms. There is no evidence at present for such differences.

The frequency of the melanic was thought to be more reliably estimated by a sample of adult males, since even their limited powers of dispersal would ensure that a sample originated from an area of several thousand square metres. The moths were collected in assembling traps at several localities during the flying season in 1968 and 1969. Females placed in these traps produced a pheronome that attracted the males which were removed each day. We do not know whether males are attracted to females of like phenotype since traps usually contained females of both types. Since there is no differential emergence of melanic and non-melanic moths a major source of error in estimates is due to inadequate sampling. Samples were kept as large as practicable to minimise this.

\section{RESULTS}

Fig. 1 shows the frequency of melanic moths in samples of more than 30 . The data from which these estimates were calculated are presented in table 3 with their standard errors. Samples from Liverpool Cathedral, Huyton, Allerton and Tranmere (sites 7, 9, 4, 14), are too small to be validly incorportated into the map but table 3 shows them to be consistent with the other larger samples. These data show some major features:

1. There is a marked cline east of the River Mersey. The frequency of the melanic rises from 10-15 per cent. to 45-50 per cent. in less than $5 \mathrm{~km}$. as one crosses Liverpool from west to east. 


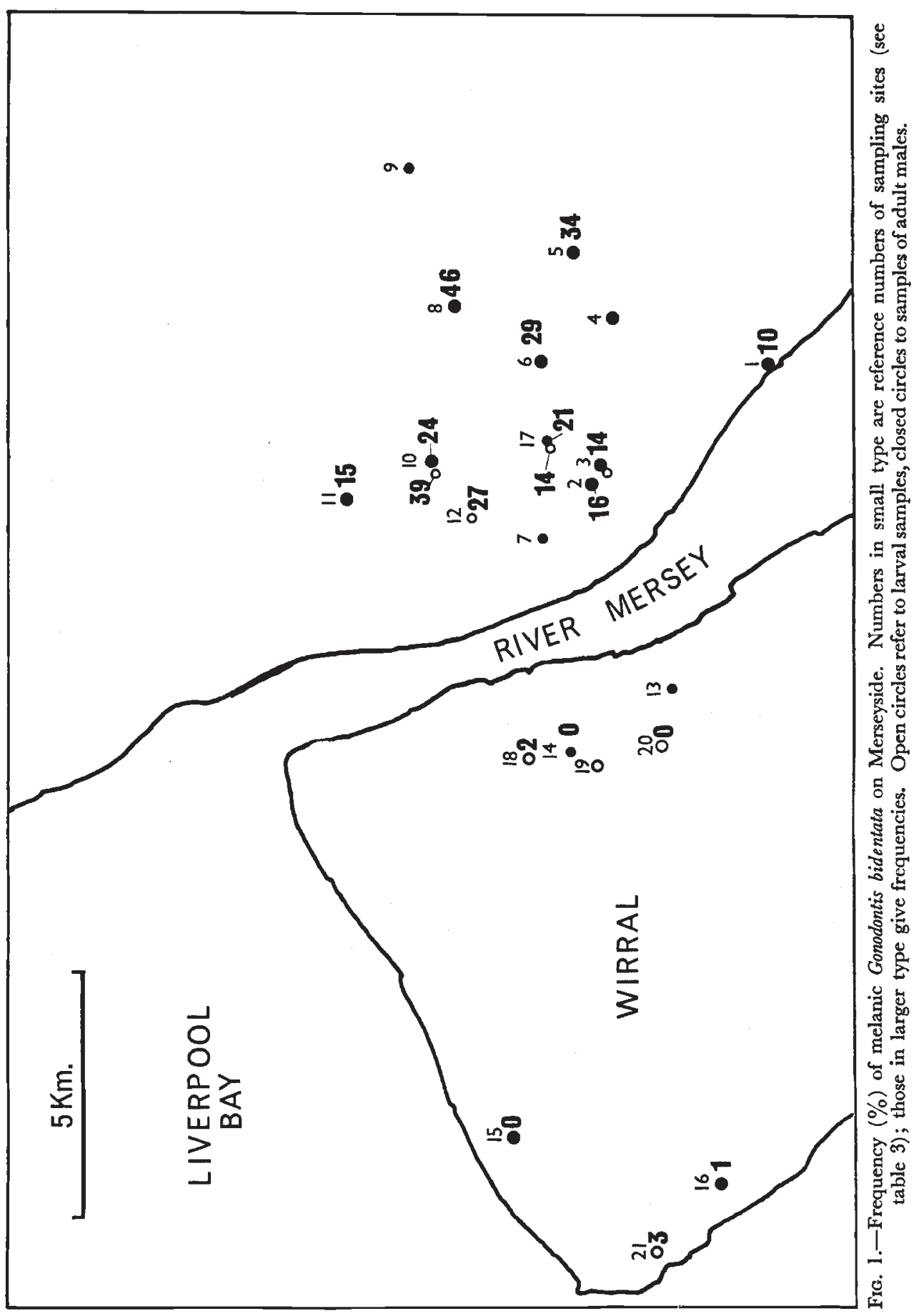


TABLE 3

Frequency of melanics in samples of Gonodontis bidentata collected on Merseyside

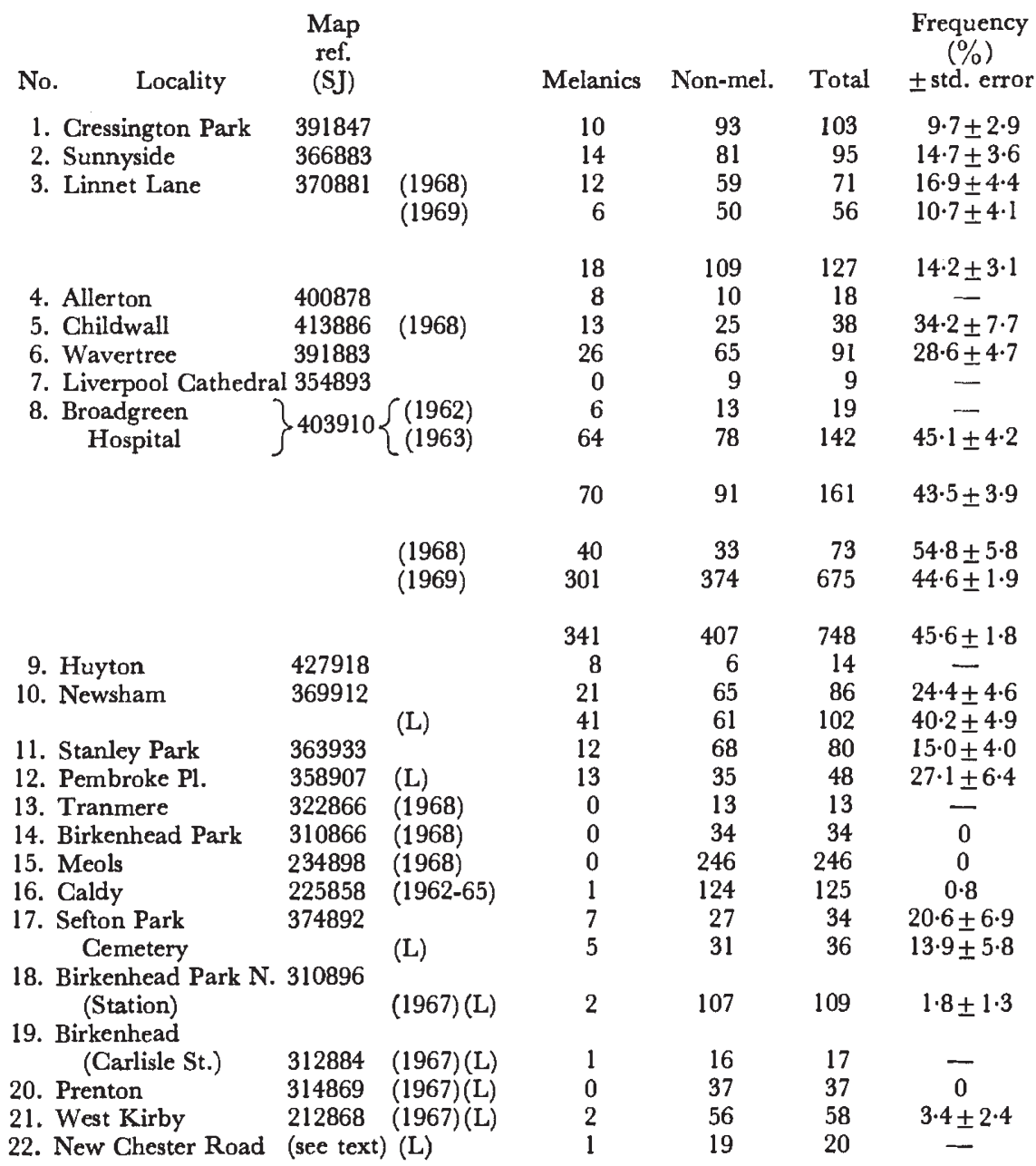

(L) Denotes larval sample. Samples were collected in October 1968 (L) or in May-June 1969 except where stated.

2. There has been no major change at Broadgreen Hospital during the last 7 years ( 7 generations).

3. The melanic seems to be present but rare throughout the northern part of the Wirral Peninsula which includes the slum areas of Birkenhead. This suggests that the melanic is not a recent chance immigrant from the Liverpool shore of the River Mersey. Samples of adults from Birkenhead $(13,14)$ are too small to reveal the presence or definite absence of the form there. Its presence may be revealed when larger samples are taken. Melanic moths howeverwere obtained from samples collected as larvae along a length of the New Chester Road (A41) about $5 \mathrm{~km}$. south of site 13 at Tranmere and from Birkenhead Park Station. 
Non-melanic $G$. bidentata show a variety of expression of pigmentation at some localities. At Stanley Park (site 11) several dark non-melanics were collected which formed the dark extreme of a continuous series. Larval samples from the north-east Wirral gave rise to similarly dark non-melanic moths. These possess darker ground coloration and many more black flecks on the abdomen and under-surface of the wings than other non-melanics. They are readily distinguishable from melanic moths whose wings and abdomens are totally black.

\section{(a) Stability of the cline}

\section{Discussion}

There is no suggestion that the melanic is becoming commoner in Liverpool as would be expected if it were spreading through a population from which it had formerly been absent; the cline appears to be stable. The frequency at Broadgreen Hospital has remained near 45 per cent. for 7 generations; if the cline were unstable major changes ought to have occurred during this time. Kettlewell (1958) presents a curve that shows the progress of spread of a gene through a population given constant heterozygous advantage and 30 per cent. selective advantage of melanic over nonmelanic. The maximum rate of change is as one would expect at about 50 per cent. close to the frequency that has been recorded at Broadgreen.

\section{(b) Factors responsible for the cline}

Haldane (1948) developed a mathematical theory of a cline for a case involving a dominant gene where the range of a species is sharply divided into two areas where markedly different selective pressures operate. This may be the case with the cline that involves $G$. bidentata but there is no obvious major discontinuity in the environment, so it is just as likely that there is a gradual change in the intensity of selection across the area in question. The River Mersey must act as a barrier to gene flow but the cline is apparently unaffected by its existence. The major change in the frequency of the melanic takes place several kilometres east of the Liverpool bank of the river. The situation may be even more complicated; Clarke (1965 and 1968) suggests that some clines may be a product of the genetic environment of the population hence show no obvious correlation with the external environment. Such clines may represent a zone of change from one series of co-adapted genotypes to another as may be the case in land snails of the genera Partula and Cepaea.

If the cline is due to a change in the intensity of selection the mechanism may involve differential predation of non-melanic and melanic moths by birds as in $B$. betularia. However the effect of air pollution on tree trunks, etc., is less drastic in the east of Liverpool (Bishop, unpublished) where the frequency of the melanic is highest. Fig. 2 shows data for mean daily smoke and sulphur dioxide concentration for the year ending March 1967 (Warren Springs Laboratory, 1967). The frequency of the melanic declines to 10-15 per cent. in some of the most heavily polluted areas east of the River Mersey and the form is very rare indeed in similarly polluted areas in Birkenhead on the west bank of the Mersey. Smokeless zones have been introduced and have resulted in a significant drop in air pollution in some parts of Merseyside. It is not yet known whether these have caused changes in frequency of the melanic in populations of $G$. bidentata. 


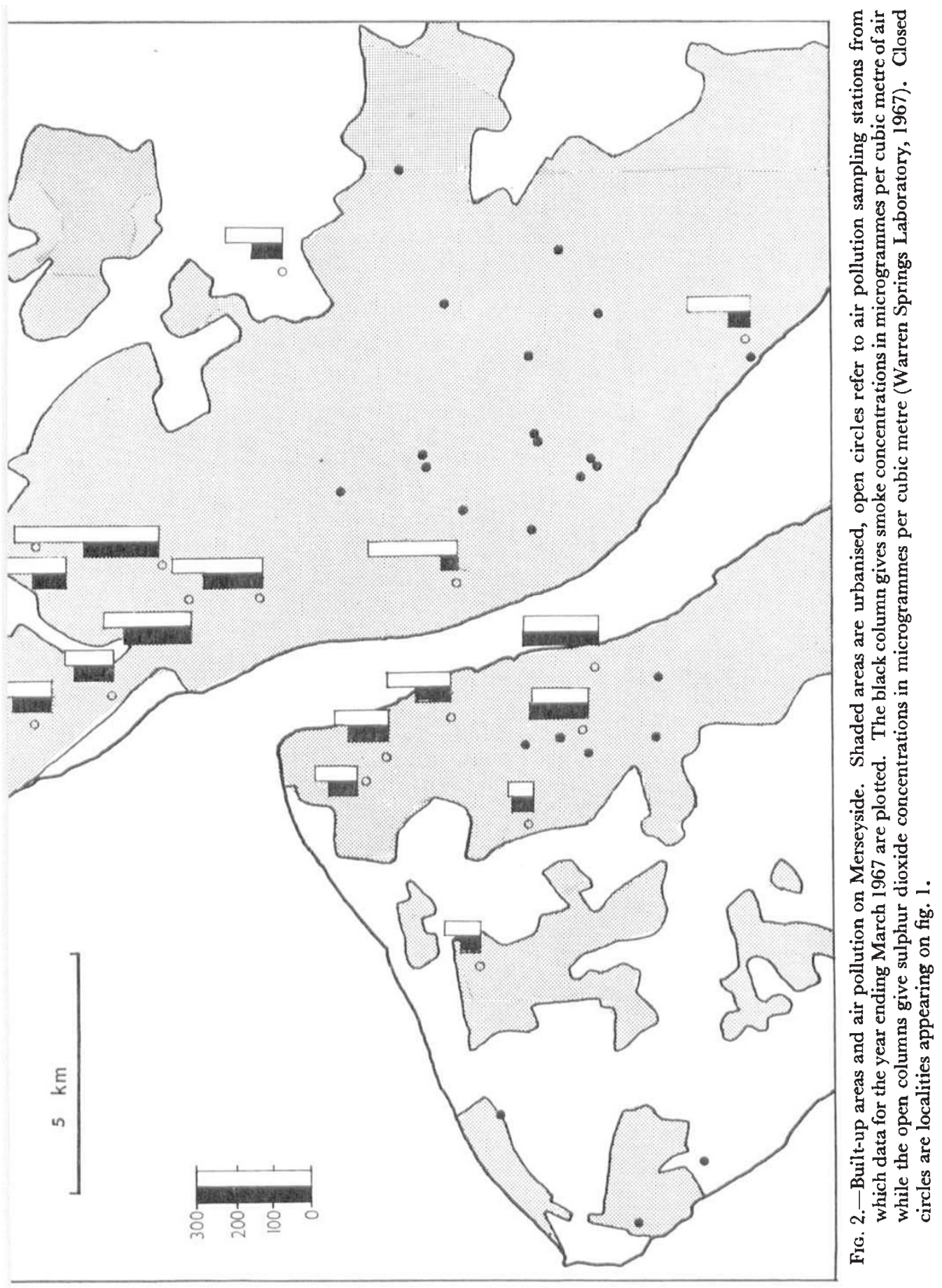


There is a striking difference between the distribution of the melanics of $G$. bidentata and $B$. betularia which strongly suggests that the two species are exposed to different selective forces. This may be because the moths rest in different places during the day or because disparate forms of selection operate at earlier stages of the life history. The forces responsible for the cline in G. bidentata are unfortunately not known but experiments are being carried out in an attempt to identify them.

The explanation advanced to account for the apparent absence of melanic $G$. bidentata from central Birmingham cannot be extended to cover the situation near Liverpool. Furthermore dark, non-melanic moths (which may be similar to those showing polygenic darkening in Birmingham) were collected from some localities in Liverpool where normal melanics were also obtained. This suggests that there may be two sorts of melanism in $G$. bidentata which represent responses to entirely different selective pressures.

Acknowledgments.-We wish to thank Professor C. A. Clarke, F.R.S., and Professor P. M. Sheppard, F.R.S., for their encouragement and criticism and for allowing us to use some previously unpublished data. Mr Tony Leibert was of great assistance and made collections of larvae for us.

\section{REFERENCES}

ASKEW, R. R., BISHOP, J. A., AND COOK, L. M. 1971. Atmospheric pollution and melanic moths in Manchester and its environs. F. Appl. Eccl. 8

Bowater, w. 1914. Heredity of melanism in Lepidoptera. 7. Genet., 3, 299-315.

ClARKE, B. 1966. The evolution of morph-ratio clines. Am. Nat., 100, 389-402.

CLARKE, B. 1968. Balanced polymorphism and regional differentiation in land snails chapter in Evolution and Environment. Yale University Press, New Haven and London.

CLARKE, C. A., AND SHEPPARD, P. M. 1966. A local survey of the distribution of industrial melanic forms in the moth Biston betularia and estimates of the selective values of these in an industrial environment. Proc. Roy. Soc., B 165, 424-439.

FORD, E. B. 1964. Ecological Genetics. Methuen, London.

haldANE, J. B. s. 1948. The theory of a cline. F. Genet., 48, 277-284.

KETTLEWELL, H. B. D. 1958. A survey of the frequencies of Biston betularia (L.) (Lep.) and its melanic forms in Great Britain. Heredity, 12, 51-72.

KeTtLewell, H. B. D. 1961. The phenomenon of industrial melanism in Lepidoptera. Ann. Rev. Ent., 6, 245-262.

SHEPPARD, P. M. 1961. Some contributions to population genetics resulting from the study of the Lepidoptera. Adv. Genet., 10, 165-216.

south, R. 1948. The moths of the British Isles. Warne, London.

WARREN SPRINGS LABORATORY. 1967. The investigation of air pollution. National survey annual summary table 1 for the year ended March 1967. 